\title{
Cristianismo progresista contemporáneo, laicismo y postmodernidad: la evolución del Centro de Estudios Cristianismo y Justicia (1981-2016) ${ }^{1}$
}

\author{
Rosa María Almansa Pérez²
}

Recibido: 19 de diciembre de 2016 / Aceptado: 27 de octubre de 2017

Resumen. El artículo pretende hacer una aportación al tema de la evolución ideológica reciente del cristianismo progresista en España y su adaptación a los cambios acaecidos tras el fin de la experiencia histórica del socialismo "real". Ello se realiza a través del caso del jesuítico Centro de Estudios Cristianismo y Justicia de Cataluña, de singular implantación y relevancia intelectual, fundamentalmente a través del análisis de sus publicaciones periódicas desde su fundación en 1981. El estudio arroja un distanciamiento creciente de las posturas iniciales del Centro respecto a ciertos postulados marxistas y a la teología de la Liberación para acercarse rápida y crecientemente a una socialdemocracia más pragmática y a planteamientos relativistas propios de la posmodernidad.

Palabras clave: Catolicismo contemporáneo; Iglesia católica; Compañía de Jesús; progresismo cristiano; laicismo; posmodernidad; Teología de la Liberación; izquierda política; socialdemocracia; relativismo cultural.

\section{[en]Contemporary progressive christianity, secularism and postmodernity: the evolution of the Center for Studies Christianity and Justice (1981-2016)}

\begin{abstract}
The article aims to make a contribution to the subject of the recent ideological evolution of progressive Christianity in Spain and its adaptation to the changes that have taken place after the end of the historical experience of "real" socialism. This is done through the case of the Jesuit Center of Studies Christianity and Justice of Catalonia, of singular implantation and intellectual relevance, mainly through the analysis of its periodical publications since its founding in 1981. The study shows a growing distancing from the initial positions of the Centre on certain Marxist postulates and the Liberation Theology to approach quickly and increasingly to a more pragmatic social democracy and to relativistic stances typical of post-modernity.

Keywords: Contemporary catholicism; Catholic Church; Society of Jesus; progressive christianity; secularism; post-modernity; Liberation Theology; political left; social democracy; cultural relativism.

Sumario: Introducción. 1. El Centro de Estudios Cristianismo y justicia y su contexto. 2. Principales planteamientos y evolución ideológica del Centro. 2.1. Entre la modernidad y la posmodernidad. 2.2. Aspectos sociales del pensamiento de Cristianismo y Justicia. 2.3. La concepción del hombre y la fundamentación de los valores en las sociedades laicas. 2.4. Las relaciones con la jerarquía eclesiásticas. 3. Conclusiones.4. Referencias bibliográficas.
\end{abstract}

1 Una primera versión de este trabajo fue presentada al XIII Congreso de Historia Contemporánea organizado por la Asociación de Historia Contemporánea y la Universidad de Castilla-La Mancha y celebrado en Albacete del 21 al 23 de septiembre de 2016.

2 Universidad Internacional de La Rioja (UNIR) (España). email: rosamaria.almansa@unir.net 
Cómo citar: Almansa Pérez, R. (2017): “Cristianismo progresista contemporáneo, laicismo y posmodernidad: la evolución del Centro de Estudios Cristianismo y Justicia (1981-2016)". Cuadernos de Historia Contemporánea, 40, 303-326.

\section{Introducción}

El presente artículo pretende realizar una aportación al tema de la evolución reciente en nuestro país del sector denominado 'progresismo cristiano'. Este término resulta aplicable por el hecho de su filiación y vinculación -aunque informales, normalmente aceptadas por sus integrantes-, con la tradición y las organizaciones de la izquierda política y sindical incluso más allá de nuestras fronteras. Dicha evolución reciente -cuyo enfoque concreto especificaremos enseguida- se quiere dibujar a través de un caso particular, pero significativo por su relevancia intelectual: el del Centro de Estudios Cristianisme i Justícia $(\mathrm{CJ})^{3 *}$, una organización jesuítica catalana nacida en 1981, vehiculada algo más tarde a través de la Fundación Lluís Espinal, que realiza una actividad de reflexión constante sobre los problemas del hombre y la sociedad contemporáneos vistos a través de los valores cristianos, dando al mismo tiempo continuidad a su labor de reflexión teológica.

En concreto, lo que aquí se pretende es, a través de este caso, profundizar en las formas de afrontar, por parte de un sector relevante del pensamiento cristiano, una conformación del mundo y del hombre contemporáneos en la que la propia cosmovisión cristiana se ve constante y crecientemente relativizada. Aunque el tema de la viabilidad del encaje del mensaje por esencia universal del cristianismo en una sociedad laica -donde se afirma la igual legitimidad de distintos proyectos globales siempre que se respeten unas normas de convivencia dadas, las cuales por tanto se sitúan de hecho por encima de aquéllos- ha sido profusamente tratado, especialmente desde disciplinas como la filosofía y la ética, lo cierto es que la naturaleza de las distintas formas de "adaptación" de los colectivos cristianos, de sus actuaciones y mensajes, así como las consecuencias que dicha adaptación hayan podido tener sobre ellos, no han recibido un adecuado tratamiento historiográfico. Un tratamiento que, además, debe tomar una perspectiva necesariamente trasnacional desde el momento en que la Iglesia española, y los diferentes colectivos a ella asociados, se encuentran no solo profundamente imbricados en una realidad que es global, sino que se sienten estrechamente vinculados, en su propia trayectoria, a la seguida por la Iglesia y por otros colectivos próximos en otras regiones del globo. Así, en el caso que nos ocupa, se hace explícita de diversas maneras la filiación del propio proyecto espiritual y social de CJ, no solo con los planteamientos y producciones fundamentales surgidos del Concilio Vaticano II (1962-1965) y de parte del periodo posconciliar, sino también con la corriente latinoamericana de la teología de la liberación, como se explicará.

En este contexto, qué duda cabe de que el viraje experimentado en el escenario mundial a partir de finales de los años ochenta del siglo XX supuso un hondo revulsivo para todos los cristianos adscritos o ligados de alguna manera a los valores de la izquierda, aunque su discurso y su praxis estuvieran distanciados del llamado "socialismo real", e incluso fueran a veces muy críticos con él. El truncamiento de la

3 *A partir de este punto se empleará la abreviatura 'CJ' para 'Cristianismo y Justicia'. 
primera experiencia histórica de envergadura para construir los valores del socialismo - a los que, de una manera o de otra, todas estas corrientes se encontraban próximas- no pudo dejar de tener sus efectos sobre aquellos. Así, por ejemplo, lo que se interpretaría mayoritariamente como la supuesta corroboración del hecho de la que la sociedad capitalista ha resultado ser la única viable no dejaba de colocarlos en una situación difícil desde el momento en que sus críticas y denuncias a las injusticias del capitalismo parecían no contar con alternativa secular.

Hemos querido, pues, acercarnos a esta andadura de transición intersecular para el caso de CJ, con el objeto de palpar, a través de algunas de sus producciones, sus posicionamientos y respuestas ante tales desafíos, así como de identificar, si fuera posible, algunas líneas de evolución general en los mismos, aun teniendo en cuenta la lógica pluralidad de sus participantes, muchos de ellos jesuitas. Para ello nos hemos nutrido sobre todo de las publicaciones periódicas, accesibles al usuario a través de su web, de sus Cuadernos y Papeles a lo largo de los treinta y cinco años de la existencia del centro hasta 2016. A este respecto, hemos seleccionado básicamente dos temas que, enunciados de forma muy general, serían los siguientes: el referido a la situación, papel y postura del cristianismo y los propios cristianos en una sociedad capitalista, secularizada, laica y democrática, así como frente a sus problemas y contradicciones; y el de la cuestión clave (dada la cosmología cristiana de partida) del fundamento de los valores en una sociedad laica y plural.

\section{El Centro de Estudios Cristianismo y Justicia y su contexto}

El Centro de Estudios CJ nace en septiembre de 1981 de la mano de la Compañía de Jesús de Cataluña a partir de un núcleo de unos quince jesuitas. El mismo se encontraba estrecha y especialmente vinculado a varias tradiciones y corrientes concretas dentro de la Iglesia. Por un lado, a su propia tradición jesuítica de sensibilidad social; por otro, como se ha adelantado, a la nueva senda marcada desde los años sesenta por el Concilio Vaticano II; y, por último, y en parte gracias a las opciones abiertas por éste, a los posicionamientos teológicos y existenciales planteados por la corriente de la teología latinoamericana de la liberación, los cuales contaron con una recepción relativamente amplia en nuestro país. ${ }^{4}$ En lo que respecta a la primera de tales raíces, la de su propio acervo, sus dos figuras fundamentales de referencia serán Pedro Clavel y Lluís Espinal. Será en 1989 cuando se cree la fundación que toma el nombre de este último y que amplía sus actividades. Ambos religiosos se distinguieron pre-

4 Uno de los fundadores de CJ, amén de otras muchas referencias que se irán haciendo en las publicaciones del centro, hace mención explícita, a los pocos años de su fundación, a la adscripción jesuítica, y con ella del propio Centro, a la senda marcada por el Concilio Vaticano II en lo que se refiere a su conocido acercamiento a la realidad secular del dolor nacido a partir de causas sociales. Cfr. Riera i Figueras, Francesc: "El Centro de Estudios 'Cristianisme i Justicia", Iglesia Viva: Revista de Pensamiento Cristiano, 134-135 (1988), p. 285. Para la justificación de tal alineamiento se remite el autor a la llamada Congregación General 32 de la Compañía de Jesús, de 1974, donde se definiría "que el "punto focal” de la vida y misión del jesuita había de ser "la opción por la fe y la justicia", realidades que había de integrar desde lo más profundo de ellas mismas." Cfr. Provincia mexicana de la Compañía de Jesús: “Congregación general 32. Decreto 4: Nuestra misión hoy”, en Pedagogía Ignaciana, 1974-1975. Disponible en: http://pedagogiaignaciana.com/GetFile.ashx?IdDocumento=467. Sobre la acogida de la teología de la liberación en España, véase González de Cardedal, Olegario: La teología en España (1959-2009). Memoria y prospectiva, Madrid, Encuentro, 2010, pp. 64-65, el cual indica incluso que, a partir de 1975, la teología española tuvo en aquella "su punto de apoyo y de orientación mayor". 
cisamente por su lucha, en distintos momentos, por los desheredados y explotados de América Latina, un continente que sirve de fuerte referencia identitaria al centro desde sus comienzos.

La situación de CJ en la línea marcada por el Concilio Vaticano II, como, especialmente en sus comienzos, por la ya citada teología de la liberación, que aprovecha este empuje eclesial fundamental, presenta pocas dudas por varias razones, como se irá exponiendo. ${ }^{5}$ Aunque sobradamente conocida por la abundantísima bibliografía generada desde su nacimiento formal a partir de la publicación de textos como La teología de la liberación, de Gustavo Gutiérrez, en 1971, y de su reconocimiento implícito en la Conferencia del Episcopado Latinoamericano (CELAM) celebrada en Medellín en 1968, ésta se caracterizará, entre otros rasgos, por su énfasis puesto en una reinterpretación teológica que parta no solo de la Palabra revelada, sino de la praxis histórica concreta. Un acontecer histórico que estaría marcado decisivamente por estructuras injustas de opresión (especialmente lacerantes en el llamado Tercer Mundo, y concretamente en América Latina) que se haría preciso analizar y revelar con el concurso de las ciencias sociales (y en particular con la confrontación con el marxismo), avanzando, así, hacia una concepción de pecado más estructural y menos exclusivamente personal. El resultado es un pensamiento teológico y una práctica pastoral marcados por la llamada "opción preferencial por los pobres" de Dios en la Historia, y que vendría inducida por el propio ejemplo de vida del Jesús histórico. Unos planteamientos de opción por los pobres, por otra parte, que habían apuntado ya en el propio concilio, especialmente con el pontificado de Juan XXIII. ${ }^{6}$

En la línea señalada, CJ se definirá a sí mismo como "un Centro de Estudios dedicado a la reflexión social y teológica", y en su equipo y actividades apostará por una decidida interdisciplinariedad al integrar a numerosos profesionales y expertos provenientes de las ciencias sociales. La fundación, por su parte, definirá asimismo su misión como la de "promocionar el diálogo entre las ciencias sociales y la teología". ${ }^{7}$ De esta forma, no solo se dividirá el Centro en dos áreas, la propiamente teológica y la social (que se encontrarán, no obstante, mutuamente imbricadas), sino que se hará patente la implicación del mismo en las problemáticas sociales -tanto nacionales como de otros ámbitos- a través de sus publicaciones y actos públicos, para los que irá contando en numerosas ocasiones con estudiosos de las ciencias sociales externos a CJ.

Aunque la mencionada vinculación con la teología de la liberación no siempre se afirma expresamente, ${ }^{8}$ lo cierto es que ésta resulta evidente por varias razones. En

5 Ya en su propia web se presenta al Centro "como respuesta a la tarea prioritaria "del servicio de la fe y la promoción de la justicia"." Cfr. Centre de Estudis Cristianisme i JUstícia: "Fundación Lluis Espinal (CJ)", en Centre de Estudis Cristianisme i Justicia, s.f. Disponible en: https://www.cristianismeijusticia.net/es/ fundaci $\% \mathrm{C} 3 \% \mathrm{~B} 3 n-11$ uis-espinal-cj. Unas palabras tomadas del llamado Decreto 4 de la ya citada Congregación General 32, por el que la Compañía trataba de encarar los retos mundiales de aquella década de los setenta a partir de los planteamientos novedosos y rupturistas del concilio respecto a la tradición anterior. Precisamente, entre otras características, la focalización de la atención sobre las relaciones entre fe y justicia, en lugar de sobre el diálogo entre fe y razón, defendido por planteamientos más tradicionales, constituye uno de los rasgos esenciales de las llamadas teologías de la revolución y de la liberación. Cfr. González de Cardedal, Olegario: $L a$ teología... pp. 64-65.

6 Batista LIbânio, Joâo: Teología de la liberación: guía didáctica para su estudio, Santander, Sal Terrae, 1989, p. 69.

7 Centre de Estudis Cristianisme i Justícia: Fundación...

8 Con ocasión del vigésimo aniversario de CJ, ya se señaló en la prensa catalana su filiación tanto a esta corriente teológica como al socialismo cristiano: López, María-Paz: "Justo y necesario. Cristianisme i 
primer lugar, por la presencia de destacados teólogos de esta corriente en las publicaciones del organismo, tales como Leonardo Boff, Jon Sobrino, Ignacio Ellacuría, Juan Luis Segundo, Torres-Queiruga, Hugo Assmann o José María Castillo. Por otra parte, uno de los más destacados teólogos no solo del centro, sino del ámbito nacional, y además responsable de su área teológica desde sus comienzos hasta 2011, el jesuita José Ignacio González Faus, no solo ha mostrado una implicación activa y permanente en las problemáticas centrales planteadas por dicha corriente teológica en sus numerosísimas publicaciones, sino que ha participado en foros y estudios que reflexionan y profundizan en muchos de sus principales planteamientos. ${ }^{9}$ Son, además, muchas las publicaciones del centro en las que se hace especial hincapié en la conocida "opción preferencial por los pobres"; ${ }^{10}$ mientras que la centralidad, ya en su propio ideario, de la lucha por la justicia y la aspiración a profundizar en sus causas como medio para superarla, supone ya un punto esencial de coincidencia. No obstante, y a pesar de lo dicho, también apuntamos aquí la hipótesis, que trataremos de justificar, de que tal savia inspiradora tiende a ir debilitándose con el tiempo, a la par que la propia teología de la liberación va perdiendo fuelle con el propio ocaso del socialismo "real".

La actividad del centro CJ y de la fundación resulta, sin duda, prolífica en sus más de treinta años de existencia. A partir de sus dos áreas ya mencionadas, la teológica y la social, ha venido celebrando seminarios anuales, cursos, mesas redondas y conferencias con las que se pretende llegar al público en general a través del tratamiento de temas de la actualidad social, política o económica. Escritos por especialistas en diferentes campos, tanto jesuitas como seglares, se han publicado asimismo hasta 2016 unos doscientos Cuadernos bimensuales y algunos más de un formato más breve (Papeles) que abordan las áreas social, teológica y espiritual con un tratamiento que se pretende riguroso, pero que procura siempre llegar al mayor público posible con un lenguaje asequible y un planteamiento didáctico. Al mismo tiempo, no se oculta la aspiración a ejercer influencia en la opinión pública y en los propios agentes sociales y responsables políticos, para lo cual se emplean medios como el trabajo en red con otros organismos, también a nivel internacional, o la actualización y diversificación de sus medios de difusión y comunicación, como vídeos, un blog o las redes sociales. Así, el impacto provocado en algunas instancias políticas por su campaña, a finales de los años ochenta, en pro de un "salario ciudadano", es uno de los hechos

Justícia cumple 20 años de reflexión sobre fe, cultura y asuntos sociales", La Vanguardia, 9 de septiembre de 2001. Disponible en: http://hemeroteca.lavanguardia.com/preview/1992/11/29/pagina52/34162769/pdf. html? search=cristianisme $\% 20 \mathrm{i} \% 20 \mathrm{justicia}$.

9 De esta forma, ya tuvo ocasión de estar presente, en 1979, junto con teólogos latinoamericanos de la liberación, en La batalla de Puebla, Barcelona, Laia, 1980. Asimismo, cabe destacar su labor de autor y editor, junto a Comblin, José y Sobrino, Jon en Cambio social y pensamiento cristiano en América Latina, Madrid, Trotta, 1993. El libro recogía las actas del Encuentro internacional del mismo título, celebrado en El Escorial en julio de 1992, que trataban de hacer balance -y también prospectiva - tras veinte años de teología de la liberación en América Latina y otros lugares del mundo. Asimismo, cabe mencionar, entre otros ejemplos, su aportación "Veinticinco años de teología de la liberación (1971-1996): teología y opción por los pobres", en Busquets, J. y Martinell, M. (eds.), Fe i teologia en la història, Facultat de Teologia de Catalunya, Barcelona, 1997, pp. 615633. En ella se adscribía el autor explícitamente a la tesis de Assmann según la cual sería "necesario salvar a la teología de su cinismo" desde el momento en que ésta se desentiende de las flagrantes injusticias del mundo, al tiempo que acusaba a la Iglesia de "verdadera falta de fe" por su supuesta tibieza en la causa por los pobres, a la que aspira a convertir en "privilegio hermenéutico" de la Iglesia.

10 Puede citarse, entre otros muchos ejemplos, Cristianisme i Justícia: Universalidad de Cristo. Universalidad del pobre. Aportación al diálogo interreligioso, Santander, Sal Terrae, 1995. 
más reseñados por los propios miembros del centro, pues piensan que se encuentra en la base de las actuales ayudas y subsidios de inserción para personas con menos recursos. ${ }^{11}$ Según se afirma, la tirada actual de los Cuadernos se acerca a unos 50.000 ejemplares, que se distribuyen por 138 países. ${ }^{12}$ Por último, CJ cuenta con una línea editorial propia al tiempo que colabora con otras editoriales afines como Sal Terrae.

El Centro y la Fundación no constituyen, naturalmente, un caso aislado en nuestro país, sino que se insertan, aun con su singularidad propia, en lo que podríamos denominar una corriente propia del movimiento eclesial católico, que se autodenomina progresista, y que se vio alentada especialmente a partir del Vaticano II. Dicha corriente, aunque heterogénea y variable, ha estado constituida por numerosas organizaciones de base, al tiempo que cuenta con una serie de instituciones e intelectuales de renombre, muchos de ellos sacerdotes, que se han visto seriamente enfrentados con la jerarquía de la Iglesia, especialmente a partir del pontificado de Juan Pablo II, caracterizado, entre otros aspectos, por su conservadurismo, su anticomunismo y su persecución a la teología de la liberación. Una tensión que se prolongó asimismo durante el papado del anterior cardenal Ratzinger y que únicamente se ha relajado con el gobierno del actual pontífice, Francisco, que ha despertado grandes esperanzas en este sector de la Iglesia.

El mencionado movimiento - que posee también importante participación laicacuenta en nuestro país con instituciones tales como el Instituto Superior de Pastoral de la Universidad Pontificia de Salamanca, el Instituto Fe y Secularidad de la Universidad Pontificia de Comillas (también jesuita) o la Escuela Bíblica; con medios de comunicación como la revista Iglesia Viva, Frontera, Atrio, Fe Adulta, Religión Digital, Alandar, Ciberiglesia, Eclesalia, Encrucillada, 21RS o Éxodo, y organizaciones, entre otras, como Redes Cristianas (en realidad una federación de asociaciones), Juventud Obrera Cristiana, Hermandad Obrera de Acción Católica, la Asociación de Teólogos y Teólogas Juan XXIII, el Centro Evangelio y Liberación, diversas Comunidades Cristianas Populares, Somos Iglesia, Foro Curas de Madrid, Movimiento Pro-Celibato Opcional y por supuesto Cristianismo y Justicia. Entre sus intelectuales descuellan nombres como los de Torres-Queiruga, José María Castillo, José Arregui, Dolores Aleixandre, José Antonio Pagola, Benjamín Forcano, Xabier Pikaza, Juan José Tamayo, Juan Antonio Estrada, Masiá Clavel o el del teólogo jesuita de CJ González Faus.

Entre sus principales reivindicaciones y aspiraciones se encuentran la de una mayor fidelidad en la Iglesia a lo que se considera la palabra evangélica original y el ejemplo de vida de Jesús de Nazaret. En general, se pretende un regreso al espíritu del Vaticano II y su constitución Gaudium et Spes (aunque no siempre se considera suficiente); una Iglesia más “experiencial” y menos dogmática, ritualista y rigorista, más descentralizada, capaz de abrirse a la sociedad y con mayor diálogo, horizontalidad y participación internas. Asimismo, se considera crucial el desarrollo de una superior sensibilidad social y compromiso ético y material de la misma con los pobres y excluidos, así como una actitud activa de denuncia de las injusticias de este mundo. Se pretende alentar iniciativas tales como la introducción del sacerdocio

11 Cristianisme i Justícia: “Cristianisme i Justícia. 30 años de reflexión por un mundo más justo”, en YouTube, 19 de octubre de 2011. Disponible en: https://www.youtube.com/watch?v=KOeGzurUo8s\#t=64.

12 Centre de Estudis Cristianisme i Justícia: "Los cuadernos de Cristianisme i Justícia", en Centre de Estudis Cristianisme i Justícia [en línea], S.f. Disponible en https://www.cristianismeijusticia.net/es/quaderns. 
femenino o el celibato opcional, y se muestran también en desacuerdo con la Iglesia oficial en cuestiones de sexualidad, reproducción y bioética. Tales sectores suelen pronunciarse en pro del diálogo interreligioso, la exploración y el reconocimiento de la riqueza inspiradora de otros credos y formas de manifestación religiosa, e incluso de opciones de vida no creyentes si se consideran auténticas, y la búsqueda de unos referentes éticos comunes mínimos entre todas ellas. Se ambiciona, en definitiva,

una teología de la liberación en perspectiva interreligiosa, intercultural e interétnica, a nivel planetario, que pueda contribuir, siquiera modestamente, a construir un discurso inclusivo del otro [...].13

Es propio también de esta corriente su defensa expresa de la sociedad laica como un modelo en el que se respeta la libertad y diversidad ideológica y de pensamiento, y donde las opciones religiosas, libre e individualmente asumidas, quedan incorporadas y relativizadas en su condición de mensajes de naturaleza universal. ${ }^{14}$

\section{Principales planteamientos y evolución ideológica del Centro}

\subsection{Entre la Modernidad y la Posmodernidad}

Cuando nace CJ en el año 1981, la teología de la liberación latinoamericana mantenía aún con vigor su esperanza mesiánica y su espíritu transformador. Eran momentos en los que se defendía incluso su vinculación con algunos aspectos del marxismo como algo legítimo y necesario, especialmente en lo que concierne a sus categorías de análisis social. Y fruto de esa recepción de la influencia marxista fue la reivindicación del proceso de liberación como de naturaleza necesariamente histórica. Un clima que era recogido por CJ en 1986 en un artículo de J.L. Segundo que era en realidad un resumen de un libro suyo en respuesta a la "Instrucción sobre algunos aspectos de la Teología de la liberación” de la S. Congregación para la Doctrina de la Fe de 1984, presidida por el cardenal Ratzinger. ${ }^{15}$ Haciendo hincapié en la realidad de la lucha

13 Tamayo, Juan José; Fornet-Betancourt, Raúl (eds.): Interculturalidad, diálogo interreligioso y liberación: I Simposio Internacional de Teología Intercultural e Interreligiosa de la Liberación. Barcelona, 11-12 de julio de 2004, Navarra, Verbo Divino, 2004, p. 6.

14 Puede verse, en relación con este último aspecto, Estrada, Juan Antonio: El cristianismo en una sociedad laica: cuarenta años después del Vaticano II (2a. ed.), Bilbao, Desclée de Brouwer, 2009, pp. 130-1. Las nuevas vías que se abren en la teología española a partir del Vaticano II y sus caminos de consolidación pueden verse en Gesteira Garza, Manuel: La teología en la España del siglo XX, Bilbao, Desclée de Brouwer, 2004, pp. 73 y ss. En particular, se alude a cómo, a partir de los años 80, se produce una división entre "una tendencia "neo-confesional" que se muestra reticente ante una "ética civil" consensuada, al considerarla desprovista de suficiente base religiosa. Mientras otro grupo importante de teólogos se inclina por la validez de la ética civil, considerándola más acorde con el espíritu del Vaticano II" (p. 118). Una crítica a este cristianismo "progresista", hasta el punto de considerarlo un "desafío radical a la fe y al cristianismo", en González de Cardedal, Olegario: La Iglesia en España, 1950-2000, Madrid, PCC, 1999, pp. 381-388.

15 Segundo, Juan Luís: "Estudio crítico sobre la Teología de la Liberación. La respuesta de J. L. Segundo al primer documento Ratzinger (síntesis y guía de lectura)", Cuadernos Cristianismo y Justicia, 13 (1986), pp. 1-21. La Instrucción se inscribía en lo que parecía ser "un ataque sistemático del Vaticano destinado a invalidar a la teología de la liberación en todas sus formas", y que había comenzado especialmente a partir de 1979 con el triunfo de la revolución sandinista en Nicaragua. Cfr. Berryman, Phillip (1989), Teología de la Liberación: los hechos esenciales en torno al movimiento revolucionario en América Latina y otros lugares, México, Siglo XXI, pp. 100-102. 
de clases, Segundo llega incluso a defender, en algunos casos, y citando a Pablo VI, el empleo de la "insurrección revolucionaria". En dicho escrito, el famoso teólogo sostenía que "la historia de la salvación no se da fuera de la historia profana", lo cual era una idea aceptada entre algunos de los más destacados representantes de la corriente. ${ }^{16}$ Ello imprimía en su praxis -a pesar de las enormes dificultades a las que se enfrentaba- y en su visión del futuro, un carácter que resulta, incluso, en algunas ocasiones, entusiasta. Así, el propio Gustavo Gutiérrez hacía extensivo este espíritu, expresado en la ya citada conferencia de Medellín de 1968, a finales de los ochenta, cuando evocaba (en la introducción a la decimocuarta edición de su obra más clásica) la declaración de los obispos latinoamericanos de que "estamos en el umbral de una nueva época histórica en nuestro continente, llena de un anhelo de liberación total", que según él se extendía también a otros lugares del mundo. Constataba, al mismo tiempo, los grandes avances de la Iglesia católica en el subcontinente. ${ }^{17}$ En este contexto de optimismo, el teólogo de CJ González Faus, aunque marcando distancias evidentes con el marxismo, defendía a finales de los setenta las afinidades de la teología de la liberación con el mismo, exigiendo la aplicación de su "rigor científico" más allá de su "ideología". ${ }^{18}$

Sin embargo, en la sucesión de estudios producidos por CJ a lo largo del tiempo, puede irse observando, en general, un progresivo distanciamiento de algunas de estas posturas iniciales, aunque se mantienen -al menos nominalmente- otros planteamientos que ya estaban presentes originalmente en el pensamiento de la teología de la liberación. Es desde luego muy llamativo un artículo de González Faus del año 1988 en el que el autor es más crítico con la modernidad (y, dentro de ella, especialmente con el marxismo) que con la posmodernidad, con la que en realidad se muestra bastante indulgente. ${ }^{19}$ De hecho, es la rápida y creciente asunción de postulados propios de la posmodernidad -aunque no siempre se asuma abiertamente-, uno de los rasgos más sobresalientes de la evolución ideológica de CJ desde los años ochenta hasta la actualidad, como trataremos de justificar. Aunque la posmodernidad es un fenómeno complejo y diverso, podemos entenderlo, en líneas muy generales, como un conjunto de manifestaciones intelectuales y artísticas -que van cobrando protagonismo a partir de los años sesenta y setenta del siglo XX- que afirman la primacía de la razón instrumental y de las lógicas contextuales en detrimento de un sentido y comprensión unificado y coherente de la existencia (los llamados grandes relatos o metarrelatos), lo que conlleva el cuestionamiento radical de nociones claves de la modernidad como las de esencia, verdad, totalidad o Sujeto. ${ }^{20}$

16 Boff había afirmado poco antes que "El Reino -categoría empleada por Jesús para expresar sua ipsissima intentio- constituye la utopía realizada en el mundo" (Boff, Leonardo: Iglesia: carisma y poder. Ensayos de eclesiología militante, Santander, Sal Terrae, 1982, p. 14). Incluso más tarde, caídos hacía poco los regímenes del Este, Casaldáliga y Vigil seguían sosteniendo una idea semejante, si bien ya hacen expreso su distanciamiento respecto al "pensamiento idealista o estructuralista" (Casaldáliga, Pedro; Vigil, José María: Espiritualidad de la Liberación, Santander, Sal Terrae, 1992, pp. 179-180).

17 Gutiérrez, Gustavo: Teología de la Liberación. Perspectivas, $18^{\mathrm{a}}$ edición, Salamanca, Sígueme, 2009, pp. 1745.

18 González Faus, José Ignacio: La batalla... p. 255.

19 González Faus, José Ignacio: "Post-modernidad europea y cristianismo latinoamericano", Cuadernos Cristianismo y Justicia, 22 (1988), pp. 1-27.

20 Aunque no nos resulta posible abundar aquí en un tema tan extenso, baste citar la definición del propio Lyotard en la obra, publicada en 1979, que más lo populariza. Así, "Simplificando al máximo, se tiene por "posmoderna" la incredulidad con respecto a los metarrelatos. Ésta es, sin duda, un efecto del progreso de las ciencias; pero ese progreso, a su vez, la presupone. Al desuso del dispositivo metanarrativo de legitimación corresponde 
Si realizamos un seguimiento sistemático de las publicaciones de CJ a partir de los años 80 , podemos comprobar que va desgastándose rápidamente la idea de la confianza en el futuro, que decae la fe en las posibilidades humanas de realizar la justicia, o más exactamente, el prometido Reino, en los confines de la historia. Ello se funda en una visión bastante pesimista de las posibilidades humanas. En el fondo, esto es consecuencia del rechazo generado hacia la idea de razón, y, por tanto, hacia las potencialidades humanas para lograr, por un lado, una comprensión coherente de la totalidad y, por otra, el distanciamiento suficiente del propio contexto en el que se halla inserto el ser humano para labrarse un conocimiento objetivo de la realidad. De hecho, basándose especialmente en Adorno y la escuela de Frankfurt (todavía herederos del marxismo), es negada la idea misma de totalidad, que se considera en esencia "totalitaria", y con ello se erosiona asimismo la confianza en la instauración utópica definitiva en el reino de lo secular:

todo cambio histórico radical que apunte a realizar más Justicia, más libertad y más humanidad, es un círculo cuadrado histórico. Justicia, libertad y humanidad son palabras que no significan nada $\mathrm{o}$, en todo caso, son realidades que el hombre sólo puede buscar por sí solo y para sí solo, y con cuentagotas. Esta es una experiencia histórica innegable. [...]

la revolución es imposible porque el hombre no es de fiar, y el hombre es precisamente el sujeto de la revolución pendiente.

La PM [posmodernidad] ha hecho también la experiencia, dura pero innegable, de que nuestra realidad es sórdida, y que la ilusión moderna no hacía más que enmascarar esa sordidez con bellas palabras altisonantes o de color de rosa, pero que $[\ldots]$ de rosa no tenían más que "el nombre". ${ }^{21}$

Desconfianza, pues, hacia la razón y lo que se considera que son sus pretensiones de supremacía, de absoluto, que pretenden en algunas ocasiones compensarse con una "fe en el hombre" que, como acabamos de observar, resulta problemática. Una fe, pues, que recela por un lado de las más ambiciosas pretensiones humanas de comprensión racional, y, por otro, que cree necesaria una separación entre el propio ámbito de fe del hombre y el de su razón, renunciando a su compatibilización o mutua penetración. Con ello no deja de producirse una ruptura en relación con el pensamiento de la patrística (por ejemplo, san Agustín: "creo para entender y entiendo para creer"). Por otra parte, la remisión a la justificación religiosa de los valores humanos - o de una naturaleza humana como tal- es algo de lo que, en general, es-

especialmente la crisis de la filosofía metafísica [...]. La condición posmoderna es, sin embargo, tan extraña al desencanto, como a la positividad ciega de la legitimación. ¿Dónde puede residir la legitimación después de los metarrelatos? El criterio de operatividad es tecnológico, no es pertinente para juzgar lo verdadero y lo justo." Cfr. Lyotard, Jean-François: La condición postmoderna, Barcelona, Planeta, 1993, pp. 10-11.

21 González Faus, José Ignacio: Post-modernidad... pp. 3-4. Los subrayados son nuestros. Juan José Tamayo, con quien teólogos de CJ coinciden en numerosos foros y algunos escritos y publicaciones, y que se encuentra muy enfrentado con la jerarquía católica, ya mostraba la misma remisión a la idea de Adorno de totalidad como "no-verdad" (Tamayo, Juan José: Otra teología es posible. Pluralismo religioso, interculturalidad y feminismo, Barcelona, Herder, 2011, p. 117). Por otra parte, en un artículo relativamente reciente, el propio Faus se refería nuevamente al carácter limitado o "fronterizo" de la razón humana y planteaba un cierto recurso a la mística y a la experiencia de solidaridad humana, especialmente con las "víctimas de esta historia", como vías de superación de la ausencia de Dios en este mundo. Cfr. González Faus, José Ignacio: “Dios?”, Cuadernos Cristianismo y Justicia, 190 (2014), pp. 1-36. 
tos autores quieren prescindir, aunque sin la afirmación de una naturaleza humana no parece posible tener fe ni no fe. Esta renuencia se produce, entre otras cosas, como veremos, por la pretensión también "universalista" de las propias religiones, así como por la aspiración de muchos de ellos de ver fundamentada la sociedad en "sus propios principios de racionalidad ética y eficacia política".22

Se produce, pues, un distanciamiento innegable respecto a los valores de la modernidad, aunque tal distanciamiento es contradictorio y no dejan de producirse nuevas referencias a los mismos. ${ }^{23}$ Así, en un epílogo de Faus al artículo de Oller inmediatamente citado, éste reivindicaba los "derechos del hombre" exaltados por la Revolución francesa como "derechos de Dios". Más adelante enaltecerá de nuevo el "eslogan típico de la Modernidad", esto es, "libertad, igualdad, fraternidad", como "expresión del significado de la existencia de Dios", y por tanto no solo realizable, sino "obligatorio". ${ }^{24}$ Todo ello a pesar de que a finales de los ochenta había sostenido que

Nuestra Modernidad confundió probablemente la llamada de la solidaridad (y de la libertad), con el mito voluntarista del "cielo en la tierra". Y este mito es infinitamente nefasto, porque acaba generando la convicción inconsciente de que no es necesaria la educación del hombre..$^{25}$

Pero a pesar de estas remisiones relativamente recurrentes a la Modernidad, lo que sí es cierto es que va consolidándose la convicción de que es necesario pasar del "gran relato" al "pequeño relato", del anhelo por la transformación de los grandes vectores de la realidad a la confianza en la incidencia de los pequeños gestos, muchos de ellos de la vida cotidiana; de la aspiración por la universalización de los grandes valores a hacer más hincapié en el valor de lo específico y lo diverso por sí mismo, sin atender demasiado al valor de la unidad; y de las acciones colectivas a la preferencia por la opción de vida personal, el gesto simbólico, el propio ejemplo. Se asienta la idea de que el hombre posee una razón débil y capciosa, que tiende a convertir en absoluto todo lo que cree verdadero $-\mathrm{y}$, por tanto, a imponerlo a los demás- y que le impide distanciarse adecuadamente de su propia tradición, situación y contexto, propendiendo a universalizarlos abusivamente. Resultaría, pues, necesario, siguiendo estas premisas, distanciarse de los grandes sistemas ideológicos de la modernidad y asumir que la realidad es inevitablemente compleja y que solo podemos acercarnos a ella de manera indirecta y fragmentaria. Y esta praxis parcial, local y multifocal es lo que permitiría, según estos autores, el florecimiento de una rica diversidad de opciones que constituiría el verdadero sustento de una sociedad democrática. Además, con todo ello se asumiría el carácter gradualista y a largo plazo de todas las acciones, además de la incertidumbre de sus resultados:

22 Una parte de este debate se puede seguir muy bien en Vives, Josep: "La democracia, más allá de los ídolos", Cuadernos Cristianismo y Justicia, 125 (2004), pp. 7, 16.

23 Así, por ejemplo, Oller Sala, Ma Dolors; Seminario De Profesionales Jóvenes De Cristianismo y Justicia: “Ante una democracia de baja intensidad, la democracia a construir”, Cuadernos Cristianismo y Justicia, 56, 1993, pp. 3-4.

24 González Faus, José Ignacio: ¿Dios? ... p. 25.

25 González Faus, José Ignacio: "Post-modernidad...”, p. 10. 
Del gran relato al pequeño relato. Pasar, de la fe en los grandes proyectos, a creer en lo más pequeño, en las acciones concretas. Dejar de creer en las grandes utopías que pretendían haber encontrado la piedra angular para cambiar las cosas y salvar a la humanidad. Un ejemplo de estos grandes proyectos han sido las grandes ideologías de los siglos XIX y XX. En la actualidad, preferimos creer en lo que es pequeño y cotidiano, aunque sea parcial, preocupándonos sólo por un determinado ámbito de la compleja realidad. Hemos perdido la pretensión de haber hallado aquello que debía resolverlo todo. A partir de esta mentalidad, han ido surgiendo los movimientos sociales (ecologismo, feminismo, pacifismo, ONG...), que, aun pretendiendo un futuro mejor, no pretenden abarcar toda la complejidad de la realidad ni pretenden haber encontrado la solución a todo. ${ }^{26}$

Resulta evidente que todas estas premisas -y otras a las que se aludirá- pertenecen al imaginario posmoderno, que en ocasiones se reivindica explícitamente. De esta forma, si, por un lado, como hemos visto, se reniega de la aspiración utópica, ésta es, sin embargo, nuevamente reclamada en otros momentos (ya que no hay cristianismo posible sin visión utópica), si bien a ésta, o bien se la saca fuera de la historia -aunque sin remitirse tampoco expresamente a la trascendencia-, o bien se la rebaja considerablemente en su estatuto ontológico. Así, se considerarán "utópicos" los "pequeños actos de solidaridad y justicia" frente a las "estructuras de mal", o bien actuaciones como la responsabilidad social corporativa, mientras que se pondrían en plano de igualdad pensamientos denominados "utópicos" como los de Rousseau, Marx o el famoso "velo de ignorancia" de Rawls. ${ }^{27}$

Sin embargo, no cabe atribuir todo este estado de cosas únicamente al influjo del pensamiento posmoderno occidental y al cambio de condiciones políticas, sociales y económicas en el mundo a partir de 1989. Efectivamente, qué duda cabe de que el descrédito del "gran relato" marxista, y la afirmación y extensión mundiales, casi imparables, a partir de entonces, de las sociedades contractuales (democráticas), vin-

26 Carrera Carrera, Joan: "Mundo global. Ética global”, Cuadernos Cristianismo y Justicia, 118 (2003), p. 11. El autor, que constituye uno de los escritores más asiduos, es jesuita y miembro del equipo. Son muchos los artículos que inciden en mayor o menor medida en este valor de los pequeños gestos y acciones, en la revitalización de lo local y en la importancia de las identidades y movimientos de carácter parcial frente a visiones del mundo más unitarias. Por poner algunos ejemplos, es significativo el título y contenido uno de los últimos Papeles publicado hasta la fecha de redacción de este texto, firmado precisamente por el equipo de Cristianisme i Justícia: "Transformemos el mundo desde el afecto y la ternura", Papeles Cristianismo y Justicia, 231 (2016), pp. 1-4. Además, pueden citarse, entre otros: Carrera Carrera, Joan: "La revolución de cada día. Cristianismo, capitalismo y posmodernidad", Cuadernos Cristianismo y Justicia, 189 (2014), pp. 1-36; Oller, M. D.; Seminario: Ante una democracia ... pp. 10-12; Durán, Elvira: “¿Hacia dónde va la democracia?”, Papeles Cristianismo y Justicia, 215 (2012), pp. 1-4; o Cortina, Adela; Carreras, Ignasi: "Consumo...luego existo", Cuadernos Cristianismo y Justicia, 123 (2004), pp. 1-27. En otras ocasiones, pretende conjugarse contradictoriamente una "mirada sapiencial y holística" con una remisión permanente a las "pequeñas cosas", como es el caso de Laguna, José: "Pisar la luna. Escatología y política”, Cuadernos Cristianismo y Justicia, 195 (2015), p. 2.

27 Carrera, J.: Mundo... pp. 3-4, 9-10. García Nieto, jesuita fundador de CJ, hablaba aún, en 1989, de la existencia de un horizonte utópico, pero que parecía más bien querer forzarse a partir de lo que consideraba el fracaso del capitalismo que observarse como una entidad con positividad propia. Cfr. García Nieto, Joan: "Proyecto de sociedad en clave de Utopía", Cuadernos Cristianismo y Justicia, 27 (1989), pp. 1-22. Es este uno de los pocos autores del Centro que mantiene en su discurso restos del utillaje conceptual marxista, que en pocos años desaparecerá completamente, si bien a pesar de su vindicación utópica no proyecta ningún contexto diferente al capitalista. Junto a él cabe destacar, casi con exclusividad, a Benjamín Bastida, quien, entre otras cosas, trata de explicar el fracaso de las sociedades del Este sin atribuirlo a un fracaso en sí de la utopía marxista. Cfr. Bastida Vilá, Benjamín: "La revolución del Este. Análisis de un fracaso", Cuadernos Cristianismo y Justicia, 40 (1991), pp. 1-13; e ídem: "El reto del trabajo", Cuadernos Cristianismo y Justicia, 93 (1999), pp. 1-27. 
culadas al capitalismo, contribuyeron decisivamente a la erosión de los planteamientos utópicos "esencialistas", lo cual, inevitablemente, vino a agravar el fenómeno, ya patente, de pérdida de arraigo social del cristianismo. ${ }^{28}$ No obstante, puede afirmarse que semillas de tal relativismo se encontraban ya en la propia teología de la liberación, como igualmente en el propio marxismo. Sin ánimo de profundizar en este punto, sí que cabe señalar que, en general, la teología de la liberación hace hincapié en que la fuente de la fe y el conocimiento humanos se encuentra fundamentalmente en la praxis, desvalorizando así indirectamente la palabra revelada y la razón. Ya J. L. Segundo afirmaba en el artículo citado que "la Iglesia va descubriendo y "haciendo la verdad" en las distintas situaciones históricas". ${ }^{29}$ También existe en la teología de la liberación, a pesar de todo, cierto pesimismo derivado de su propio historicismo: "el cristianismo puro no existe, no ha existido ni puede existir. Lo divino se da siempre en mediaciones humanas", afirma Boff. ${ }^{30}$ Unos aspectos estos que llevarán más lejos en general los teólogos de CJ. Así, en un artículo conjunto de finales de los noventa, afirman que "la palabra cristiana es ante todo una palabra "acogedora" antes de ser, y para poder ser, una palabra "explicativa". Y más en una época como la actual, tan consciente de la intrínseca ambigüedad e insuficiencia de todo lenguaje." 31 Por su parte, González Faus ya había dicho que la teología de la liberación "no se apoya en ninguna teoría", sino en hechos, y pasa de posicionarse contra las "divinas palabras" de la modernidad, especialmente contra la de "revolución", a sentenciar que "en esta vida no cabe ninguna gran palabra". Y precisamente apela al cristianismo latinoamericano como alternativa (a la modernidad especialmente) por el hecho de que "la Teología de la Liberación no es hija de la modernidad europea sino del dolor latinoamericano". ${ }^{32}$ Y ello a pesar de que el propio Gustavo Gutiérrez, uno de sus fundadores, en el mismo año, hablaba de las aportaciones de la modernidad respecto al reconocimiento los derechos de la persona, lo cual habría influido en el propio desarrollo de "lo mejor de la teología moderna", incluyendo la de la opción preferencial por el pobre, sin negar por ello que "la matriz histórica de la teología de la liberación se halla en la vida del pueblo pobre". ${ }^{33}$

28 Para un seguimiento más detallado y a largo plazo de este tema, puede verse el capítulo de nuestra autoría "Evolución de las Declaraciones universales de derechos y relativización de las fuentes de la moral religiosa", en Miguel Rodríguez Blanco; Juan González Ayesta (coords.); Religión y Derecho Internacional, Granada, Comares, 2013, pp. 87-125.

29 Segundo, Juan Luis.: "Estudio crítico...“, p. 18. Boff, por ejemplo, ya incide en las limitaciones de la razón humana (BOFF, Leonardo: Iglesia... p. 30). Y Casaldáliga y Vigil hablan de la „primacía de la praxis“, si bien subrayan aún el carácter unitario e integral de la realidad (Casaldáliga, Pedro; Vigil, José María: Espiritualidad... pp. 280-281).

30 Boff, Leonardo: Iglesia..., p. 171.

31 Cristianisme i Justícia: "El tercer milenio como desafío para la Iglesia", Cuadernos Cristianismo y Justicia, 91 (1999), p. 14. Los subrayados son nuestros. En el mismo sentido, Carrera Carrera, Joan: "En busca del Reino. Moral para un nuevo milenio", Cuadernos Cristianismo y Justicia, 101 (2000), p. 21. Asimismo, Laguna, José: "¿Y si Dios no fuera perfecto? Hacia una espiritualidad simpática”, Cuadernos Cristianismo y Justicia, 102 (2000), p. 20, quien considera que "el hacer cristiano es un presupuesto esencial de la oración, y no sólo una exigencia ética derivada de una fe ya constituida" y que "nuestra acción nos llevará a preguntarnos por la "perfección" divina".

32 González Faus, José Ignacio: La batalla..., p. 256; González Faus, José Ignacio: Post-modernidad..., p. 11.

33 Gutiérrez, Gustavo: Teología... pp. 31, 36. 


\subsection{Aspectos sociales del pensamiento de Cristianismo y Justicia}

El debilitamiento progresivo de la fe, en el caso que nos ocupa, en una proyección o realización secular de la propia escatología cristiana, posee hondas repercusiones, que resultan visibles en numerosos aspectos, desde las reconsideraciones acerca del estatus ontológico humano, que gana en incertidumbre y ambigüedad, hasta los relativos a las múltiples dimensiones de su espiritualidad y sociabilidad. Por otra parte, es innegable que se ha bebido a fondo de las fuentes de la modernidad, y que muchas de estas huellas perviven y se perpetúan en la posmodernidad. Seguramente una de las más destacadas -y que resulta palpable en las producciones de CJ-es la consideración del carácter contractual de la sociedad. Como es sabido, mientras que el cristianismo predica la solidaridad humana precisamente por su creencia en que ésta se arraigaría en el carácter fraternal del hombre, el cual este último estaría llamado a desarrollar y culminar, el pensamiento burgués de la modernidad viene a considerar la sociedad esencialmente como fruto de un contrato que se establece por razones de conveniencia. Esto conduce a una situación en la que van tomando primacía los proyectos individuales y particulares de vida. Como culminación del proceso, la postmodernidad concibe la figura humana definitivamente como contingente, mientras que las relaciones entre los hombres toman el carácter de "juegos" o conjunto consensuado de normas para la consecución de fines particulares. El único fin universal admitido sería la aseguración de la continuidad de todos ellos. ${ }^{34}$ Precisamente, resulta perfectamente observable en muchas de las publicaciones del centro una creciente consideración de la sociedad como un conjunto mayoritariamente aceptado de normas de convivencia. Dentro de ellas cabría desarrollar proyectos particulares -o éticas propias, muchas veces de "máximos"- que deben encontrarse en continuo "diálogo" mutuo y que aspiran a ejercer, compitiendo pacíficamente entre sí, su "influencia" sobre el contexto social. Dentro de ellas se encontraría, lógicamente, la propia ética cristiana. ${ }^{35}$

De esta forma, la sociedad democrática es entendida, fundamentalmente, como el ejercicio de un juego de libertades tomadas en un sentido preferentemente individual. Aunque en incontables ocasiones se hacen llamamientos para trascender el individualismo existente y crear una sociedad "más" fraternal, lo cierto es que éste no deja de constituir un desiderable de carácter ético que trata de hacerse atractivo "desde fuera", esto es, sin que exista la convicción de que tal fraternidad constituya una dimensión esencial que pueda conformar por sí misma las relaciones sociales. De esta manera, nos encontramos con una imagen de un hombre frágil y habitado por una "soledad esencial" que, para consolarse, "necesita" de los otros para "sentirse vivo". ${ }^{36} \mathrm{E}$, igualmente, encontramos frecuentes alusiones a la exigencia de constituir nuevos "contratos sociales" para paliar nuestras crisis actuales, llegándose incluso

34 Puede verse, en este sentido, como ejemplo significativo, por su extensión, la concepción de la justicia del filósofo norteamericano John Rawls (autor de referencia entre algunos autores de CJ), que parte del hecho de la impracticabilidad de la existencia de un fin común asumido desinteresadamente por todos. Cfr. Rawls, John: $L a$ justicia como equidad, Paidós, Barcelona, 2002, p. 98.

35 González Faus, José Ignacio: "La difícil laicidad", Cuadernos Cristianismo y Justicia, 131 (2004), pp. 1-24. Carrera Carrera, Joan: "Una relación difícil. Cristianismo y sociedad desde la perspectiva ética", Cuadernos Cristianismo y Justicia, 170 (2010), pp. 1-32.

36 Cristianisme i Justícia: "Transformemos...", p. 1. 
a apelar a la "urgencia de conciliar "contrato social" y "fraternidad"”. ${ }^{37}$ Ello tendría su explicación en el hecho de que el hombre sería también un "homo oeconomicus", aunque "no solo", y por tanto "con capacidad de deliberar y decidir también según intereses comunes y generalizables". ${ }^{38}$ De lo que se deduce que su dimensión fraternal no constituye sino una esfera más de su existencia -por vital que sea desde el punto de vista de su supervivencia el entenderse con sus semejantes- y, por tanto, no la dimensión esencial que lo conformaría como tal. Aunque el propio Faus defiende que la lucha por la fraternidad y la justicia constituye el único sentido auténtico de la vida humana, su radical escepticismo ante la razón y la capacidad de felicidad, unido a la negación de la existencia de una meta histórica donde tales valores se realicen y a la constatación de un palmario "Dios ha muerto" que nos aísla de él a nivel social e histórico, hacen de tal aserto un mero acto de fe. ${ }^{39}$

Recogiendo toda la tradición propia, muchos de estos colaboradores hacen hincapié en el principio básico de que la sociedad debe construirse desde y para el pobre. Pero en este punto se enfrentan también a numerosas paradojas, puesto que la lucha contra la pobreza viene a contemplarse como una especie de trabajo perpetuo para el que no se entrevé su fin. A lo máximo que se aspira, al parecer, gracias a la función redistributiva del Estado del bienestar, es a constituir o mantener una "sociedad de clases medias" "40, lo cual presupone, por definición, la existencia tanto de clases altas como bajas, aunque sean reducidas. Y ello porque la pobreza, como llega a sostenerse en alguna ocasión, "es una realidad eterna de la raza humana", lo cual no deja de ser contradictorio no solo con toda la profusión de artículos que la denuncia como algo escandaloso, sino también con las pretensiones de instaurar un "contrato social" para "erradicarla". ${ }^{41}$ Así, contra lo que parece clamarse es contra las desigualdades elevadas o extremas, pero no contra la desigualdad en sí en los niveles de vida, considerada "razonable" porque parece justificarse por criterios, entre otros, de carácter meritocrático. ${ }^{42}$ En algunas ocasiones, llega incluso a apelarse al argumento instrumental de que una desigualdad "excesiva" hace reticentes a los menos favorecidos al "pacto social de convivencia", aparte de ser ineficiente económicamente. ${ }^{43}$ En el fondo, pues, parece haberse asumido el famoso "principio de diferencia" rawlsiano. Y aunque en numerosos artículos se señala al capitalismo como la raíz de las injusticias y las "inicuas desigualdades", raramente se propone su superación o eliminación. Por el contrario, se aspira a la introducción de medidas que compensen o palien dichos efectos, fundamentalmente mediante la acción de un Estado benefactor que, por medio de un sistema fiscal adecuado, corrija la tendencia a la ampliación constante de las diferencias de renta. De esta forma, en pocos años queda desechado casi com-

37 Laguna, J.: "Pisar...", p. 29. Entre otros muchos ejemplos, Mateos, Óscar: "Hacia un nuevo contrato social", Papeles Cristianismo y Justicia, 217 (2013), pp. 1-5.

38 Oller, Ma Dolors; Seminario: Ante una democracia... p. 3. Los subrayados son nuestros.

39 González Faus, José Ignacio: "Nada con puntillas: fraternidad en cueros. La lucha por la justicia en una cultura nihilista", Cuadernos Cristianismo y Justicia, 166 (2010), pp. 1-32.

40 Miralles, Josep: "El Estado del bienestar. Debates y perspectivas", Cuadernos Cristianismo y Justicia, 49 (1992), p. 5.

41 Sebastián, Luis de: “Capitalismo y democracia en el siglo XXI”, Cuadernos Cristianismo y Justicia, 99 (2000), p. 8 .

42 Entre otros, González Faus, José Ignacio: "El naufragio de la izquierda", Cuadernos Cristianismo y Justicia, 177 (2011), pp. 3, 9-10. A pesar de lo cual, el propio autor realizará más adelante una defensa encendida de la igualdad y la fraternidad. Cfr. González Faus, José Ignacio: ¿Dios? ... p. 25.

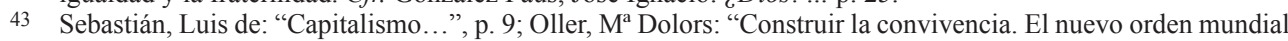
y las religiones”, Cuadernos Cristianismo y Justicia, 157 (2008), pp. 13-14. 
pletamente el análisis de tradición marxista de algunos autores, que consideraba al Estado un instrumento esencial para la preservación de las relaciones de clase, para adoptarse mayoritariamente el punto de vista de la socialdemocracia, que considera al Estado como un instrumento creado con vistas a la defensa de los más débiles. ${ }^{44}$

Así, cuando se apela a argumentos tales como que "un nuevo modelo de solidaridad [...] consiste no en "repartir entre los menos iguales los excedentes de los más iguales (mecánica redistributiva del Estado del Bienestar que no modifica sustancialmente los privilegios de los más fuertes), sino en organizarlo todo desde los derechos de los menos iguales", de los más débiles" "45, no se recurre tanto a la denuncia en sí de esta desigualdad como a la "necesaria" "toma de conciencia" de todas las partes para asumir estas exigencias éticas. De esta forma, se aduce, no solo la ciudadanía debería tornarse más participativa e implicada en distintas formas de organización y pacífica presión social, superando un individualismo muy bien arraigado (como se reconoce), sino que aquellos que concentran los principales recursos económicos y los defienden a través de sus vinculaciones políticas tendrían que ceder finalmente a esta presión ciudadana y abrir los cauces de participación democrática en la gestión de los recursos y la participación política. Al mismo tiempo, consideran algunos de estos autores que se podría llegar a crear una nueva "cultura obrera", a través del asociacionismo y la convivencia, para contrarrestar la "semidictadura económica y mediática" existente en las sociedades capitalistas, mientras que buena parte de los beneficios empresariales se desviarían, mediante procedimientos fiscales, en pro de la creación de puestos de trabajo. ${ }^{46}$ González Faus, por su parte, apela en uno de sus artículos a la figura del empresario que sacrifica sus intereses en pro del bien común. ${ }^{47}$ Todo lo cual no deja de constituir, a su vez, una suerte de utopía. De esta forma, se apela a la movilización de las fuerzas sociales y morales para el logro de una regenerada democracia, pretendiéndose, en algún artículo que supera la visión del marco nacional, una organización mundial controlada democráticamente, precedida por la idea de bien común, en la que no existan aspiraciones de exclusivismo ni preponderancia unilateral. ${ }^{48}$ Así pues, se demanda, a nivel nacional e internacional, un "control democrático", especialmente de los poderes económicos, ante lo que interpretan como la deformación y desnaturalización de las democracias actuales. ${ }^{49}$

44 Epílogo de González Faus en Camacho, Ildefonso: "Pagar los impuestos? Una polémica cuyo fondo es el futuro del 'Estado del Bienestar'“, Cuadernos Cristianismo y Justicia, 36 (1989), p. 32. Sin embargo, años más tarde (1997) también afirmaría el propio Faus que "la caída del Este está coincidiendo con la caída del Estado de bienestar, y demuestra que éste no era la figura humana del capitalismo, sino sólo su piel de cordero a la que hubo que recurrir inevitablemente ante la amenaza comunista. Pero vencida la amenaza, el sistema puede recuperar su verdadero rostro inhumano.” Cfr. González Faus, José Ignacio: Veinticinco..., p. 626. Es llamativa la cantidad de artículos de CJ que se dedican en mayor o menor grado a cuestiones fiscales, en las que se cifra buena parte de la solución para la paliación de las crecientes desigualdades. Cfr., por ejemplo, los artículos de Xavier Casanovas, director de CJ: Casanovas, Xavier: "Y con los impuestos y el sistema fiscal, ¿qué hacemos? \#201electoral", Blog de Cristianisme y Justicia, 19 de junio de 2015. http://blog.cristianismeijusticia. net/?p=12425\&lang=es; y Casanovas, Xavier: "Se confirma: Hacienda no somos todos", Blog de Cristianisme y Justícia, 13 de enero de 2016. http://blog.cristianismeijusticia.net/?p=13107\&lang=es.

45 Oller, Ma Dolors: Seminario "Ante una democracia...", p. 5.

46 Díaz Salazar, Rafael: "Un nuevo ciclo para la izquierda", Cuadernos Cristianismo y Justicia, 59 (1994), pp. $1-20$.

47 González Faus, José Ignacio: "El naufragio...”, p. 27.

48 Oller, Ma Dolors: "Un futuro para la democracia. Una democracia para la gobernabilidad mundial”, Cuadernos Cristianismo y Justicia, 115 (2002), pp. 1-29.

49 Oller, Ma Dolors; Seminario "Ante una democracia...,", p. 2. 
A pesar de que, como queda dicho, existen en las publicaciones de CJ duros párrafos contra el capitalismo como generador de injusticias, suele darse por bueno el papel del mercado en la asignación de recursos sociales, a pesar de que se apunta también a él como origen de la desigualdad, la violencia y la injusticia. ${ }^{50}$ En algunos casos, llegan a aceptarse determinados presupuestos de la lógica económica neoliberal. Josep Miralles, por ejemplo, sitúa la eficacia del mercado en el hecho de sustentarse en la persecución del propio interés, y no en el altruismo. ${ }^{51}$ De esta forma, según este autor, sería en el egoísmo personal, y no tanto en la solidaridad - que constituye sin embargo la base de la doctrina cristiana- donde se encontraría el fundamento de los principales logros de las sociedades actuales. Es por ello por lo que se hace necesaria la introducción de mecanismos de solidaridad en la dinámica social, los cuales quedan así circunscritos al nivel de correctivos. La solidaridad, de hecho, queda implícitamente disociada de la noción de justicia, al ser ésta en realidad inaplicable, e, incluso, indeseable. Así, el propio equipo en conjunto de CJ considera que la justicia radica en darle a cada cual lo que le corresponde, lo que desembocaría, según él, en una meritocracia que requeriría sistemas de compensación. Por ello apela a la misericordia como algo que trasciende la justicia. ${ }^{52}$ La justicia quedaría, pues, de hecho, como algo en último término contradictorio con el impulso humanitario y solidario presente en el hombre.

La preocupación, muy palpable, acerca de que las democracias de todo el mundo, y concretamente la española, se encuentren en un proceso de deterioro por el hecho del "acoso" al que la someterían "los mercados", con el consiguiente vacío de sentido de sus instituciones, lleva a que algunos de estos autores hagan alusiones favorables al movimiento "15M"-iniciado en 2011 en nuestro país-, a las "plazas" y a las "mareas". Todo ello en una línea que mantiene numerosos puntos de contacto tanto con planteamientos socialdemócratas como, incluso, con aquellos insertos en la órbita propia de la posmodernidad: valoración por sí misma de la variedad y diversidad que tales movimientos traerían consigo; estimación también positiva del papel de la propiedad privada y el mercado en nuestras sociedades (se critica, por ejemplo, que el mercado se haya apartado del fin que supuestamente le correspondería -distribución eficiente de bienes y servicios- y que se haya convertido en "un fin en sí mismo"); renuncia explícita al lenguaje de "clase", remitiéndose a una "complejidad" de nuestras sociedades que lo haría inservible; valoración de la creación de "alternativas" a pequeña escala, etcétera. Así, por ejemplo, se critica que haya dejado de funcionar el "ascensor social" (Mateos), al tiempo que también se afirma que la crisis de la izquierda es debida a que se haya abandonado el ideal de "la tendencia a la igualdad entre todos los seres humanos" (Faus). Al mismo tiempo, puede a veces observarse una valoración del factor tecnológico como configurador por sí mismo de

50 Entre otros, González Faus, José Ignacio; Pascual, María Luisa: "Cárceles y sociedad democrática", Cuadernos Cristianismo y Justicia, 45 (1992), pp. 1-24, quienes apuntan que el capitalismo, a pesar de la injusticia social que genera, es "en otros aspectos tan eficaz". Renau, Jesús: "Formación social en la escuela y proyecto de sociedad (una visión cristiana)", Cuadernos Cristianismo y Justicia, 48 (1992), pp. 1-18. Este autor critica con dureza al capitalismo; no obstante, los medios para modificar las "estructuras sociales" serían "una buena ley, una política honrada y eficaz [o] la administración pública al servicio de los ciudadanos". Por su parte, Luis de Sebastián llega a situar la debilidad del capitalismo en la acumulación monopolística y en la ausencia de mercado en el interior de las empresas, lo que las convertiría hasta cierto punto en poderes autoritarios regidos por una suerte de planificación central. Cfr. Sebastián, Luis: "Capitalismo...", p. 6.

51 Miralles, Josep: “E1 Estado...,", pp. 10-11.

52 Cristianisme i Justícia: "Transformemos...", p. 4. 
las relaciones humanas. Así, Elvira Durán hace explícito su deseo de que

la tecnología, que permite evitar intermediaciones sin valor, que pone en cuestión formas obsoletas de hacer política, permita asimismo construir una sociedad más equitativa, más justa, o en palabras de Rosanvallon, "una sociedad de iguales", ${ }^{53}$

\subsection{La concepción del hombre y la fundamentación de los valores en las sociedades laicas}

Entre los autores de CJ parece haberse asumido una visión del ser humano muy próxima a la visión que nos ofrece la filosofía posmoderna. En efecto, parece darse por supuesto que el hombre nada es en sí mismo, sino que está más bien dotado de una plasticidad casi infinita y una radical indefinición que sería la que le proporcionaría, conforme a la visión posmoderna, su libertad. Un planteamiento que parece hallarse en contradicción con la tradicional concepción cristiana del hombre según la cual éste encontraría en su amor a Dios y al prójimo la clave de su propia humanidad. Sin embargo, resulta compatible con aquélla -también presente en el propio cristianismo- que interpreta que es la libertad la que lo proveería de capacidad tanto para aceptar como para negar a Dios.

De esta forma, la balanza parece inclinarse aquí del lado de una concepción personalísima del hombre, capaz de elegir desde la nada entre el bien y el mal (lo que supuestamente explicaría que se pueda hablar de "méritos" religiosos). De ello se extrae que los remedios sociales acabarían descansando cada vez más en opciones puramente individuales. Todo lo cual posee una influencia radical en las reflexiones acerca del fundamento de los valores sociales, especialmente en el ámbito de sociedades axiológicamente plurales. De esta forma, la fórmula mayoritariamente aceptada es la del recurso a la "ética mínima", tomada tanto de la Escuela de Frankfurt como de su posterior reformulación por parte de la filósofa (afín a CJ) Adela Cortina. Esta ética mínima constituiría una especie de reunión de elementos esenciales coincidentes o comunes entre diferentes éticas y visiones del mundo, a la que se dotaría de una supuesta universalidad. No constituiría, sin embargo, un nuevo "gran relato", sino que su construcción respondería al principio dialógico y consensual. ${ }^{54} \mathrm{De}$ esta forma, se da por hecho que las religiones como tales deben dejar de constituir el referente inmediato de cualquier ética universal, si bien principios fundamentales de las mismas quedarían recogidos en sus formulaciones, e incluso dichas formulaciones se encontrarían en buena medida inspiradas por lo más granado de las tradiciones religiosas.

Se llega de esta manera a la situación según la cual la Declaración Universal de los Derechos Humanos - en cuanto formulación secularizada- acaba considerándose de hecho un referente ético más universal que el propio cristianismo, contemplado como una expresión de alcance más restringido por su propia radicalidad y su sustentación en la fe. ${ }^{55}$ Junto a ello, acaba arribándose a una concepción subjetiva de las religiones desde el momento en que se apela a sus contenidos porque constituyen

53 Durán, Elvira: “¿Hacia dónde...?”, p. 4. Los aspectos aludidos son todos ellos visibles en distintas publicaciones: Mateos, Óscar: "Hacia un nuevo...”; González Faus, José Ignacio: El naufragio...; Carrera, Joan: La revolución...

54 Cfr., entre otros, Carrera Carrera, Joan: "Identidades para el siglo XX", Cuadernos Cristianismo y Justicia, 147 (2007), pp. 1-33.

55 Por ejemplo, Carrera, Joan: Una relación... pp. 1-32. 
fuentes de moral muy difícilmente sustituibles, pero siempre que éstas se mantengan como "iconos del Misterio", como vías personales y experienciales hacia un Absoluto siempre "inaprehensible", pero nunca como fuentes de moral "heterónoma". ${ }^{56} \mathrm{De}$ hecho, se desconfía de ellas por sus pretensiones de

apropiarse del Absoluto, buscado por todas las religiones, lo cual las pervierte, haciendo que su vocación universalista esté permanentemente amenazada de convertirse en totalitarismo. ${ }^{57}$

Se manifiesta, así, una especie de conciencia crítica de la historia del propio cristianismo, la cual se entendería menos como un proceso doloroso pero inevitable en el supuesto largo curso de la humanidad en la aprehensión correcta de la palabra de Dios que como deformaciones derivadas de la propia naturaleza del hombre y de las mismas religiones. "El agudo sentido cristiano de la trascendencia de Dios (a pesar de Su cercanía)" pudiera estar en la base de todo ello. ${ }^{58}$

En este contexto, se llega a la conclusión de que el necesario fundamento moral de las sociedades laicas debe ser la búsqueda del "bien común" basado en el "amor a lo humano", aunque se admite que su justificación en última instancia difícilmente puede ser sino religiosa. ${ }^{59}$ En efecto, la carencia de un sólido fundamento antropológico en la mayoría de las formulaciones laicas sobre los derechos humanos hace que los propios autores de CJ deban reivindicar el respeto a estos últimos apelando a unas determinadas "reglas de juego", y no a una determinada realidad ontológica humana. Ya vimos cómo se recurre a la idea de contrato en sus propuestas de resolución de desequilibrios y carencias de todo tipo, incluso a un "contrato ético que vuelva a dar sentido y perspectiva a la aventura humana". ${ }^{60}$ Por otra parte, el papel del cristiano en las mencionadas sociedades laicas vendría a deducirse del principio de que "la religión es cosa de los ciudadanos concretos" -y no, por tanto, un proyecto social que pudiera construirse también con los no creyentes-, por lo que los valores de la convivencia son los únicos que pueden convertirse en absolutos. ${ }^{61}$ Valores, pues, que pudiéramos llamar regulativos o mediatos, pero no relacionados con fines últimos. Y ello sería así aunque teóricamente los cristianos no renuncien a luchar por "el "reinado de Dios", cuyas repercusiones sociales y políticas son innegables." ${ }^{2}$ En caso de disenso - en el contexto de sociedades democráticas y laicas- hacia realidades que se consideren deshumanizadoras, éste se plantearía, pues, preferentemente desde el ámbito individual, abordándolo desde el diálogo y el propio ejemplo, si bien se admite que dada nuestra actual pluralidad es difícil establecer "qué cosas pueden ser admitidas dentro del bien común y cómo tiene que ser entendido este bien común”. ${ }^{63}$

\footnotetext{
56 Véase a este respecto, sobre todo, Oller, Ma Dolors: Construir..., pp.18-20.

57 Ibídem, p. 19. También en este sentido, Melloni Ribas, Xabier: "Los ciegos y el elefante. El diálogo interreligioso", Cuadernos Cristianismo y Justicia, 97 (2000), p. 3.

58 González Faus, José Ignacio: La dificil... pp. 6, 16.

59 Ibídem, p. 20. Y también VIVES, Josep: La democracia... pp. 1-26.

60 Oller, $\mathrm{M}^{\mathrm{a}}$ Dolors: Un futuro... p. 18; Ídem, Construir..., pp. 13-14.

61 Esta constituye, en efecto, una concepción muy asentada de la laicidad. Cfr. Peña-Ruiz, Henry; Tejedor De La Iglesia, César: Antología laica. 66 textos comentados para comprender el laicismo, Universidad de Salamanca, 2009 , p. 46.

62 González Faus, José Ignacio: La dificil... pp. 4-9.

63 Carrera, Joan: Una relación..., p. 15. El propio recurso a la objeción de conciencia no dejaría de ser una "valoración subjetiva de una ley o de una orden emitida" (p. 18).
} 


\subsection{Las relaciones con la jerarquía eclesiástica}

En el ámbito de las reflexiones más puramente religiosas y eclesiales, CJ mantiene una postura muy crítica con la jerarquía católica por su "verticalismo", su falta de democracia interna (aunque prefiere aludirse a la "comunión" y la "sinodialidad" dentro de ella), su "helenismo" y su modelo gregoriano de Iglesia universal. Se reivindica, pues, nuevamente, un catolicismo más separado de las formulaciones racionales y un acercamiento a la experiencia y las fuentes evangélicas: "la Iglesia institución parece querer convertirse de guardiana de la revelación en propietaria de la razón", se dice ${ }^{64}$ Existe, de hecho, desde momentos tempranos en la andadura del centro, una cierta desconfianza hacia la formulación dogmática de la fe, e incluso hacia todo el proceso de construcción racional y conceptualización realizado históricamente a partir del mensaje revelado. Así, González Faus ponderará la autenticidad del cristianismo latinoamericano, el cual, acendrado por el sufrimiento del subcontinente, se tomará verdaderamente "en serio al hombre Jesús y su muerte". Un cristianismo, pues, que no se sentirá tentado por "los religiosismos abstractos occidentales" y que no atenderá sino a "la Palabra de Dios hecha palabra humana, $[\ldots]$ [a] las "mayúsculas" despojadas de su condición "divina" para entrar en las minúsculas de nuestra realidad." 65 Incluso se recurrirá a la figura de Jesús de Nazaret como hombre como referente que "podría unir a las religiones porque su oferta es una oferta de plena humanización ("pescar hombres") más allá de que se crea o no en su divinidad." 66 También se apelará a una necesaria "inculturación del cristianismo en el mundo moderno", solo posible mediante el alejamiento de la "helenización del cristianismo" que habría llevado a "la pérdida de sus raíces bíblicas." ${ }^{67}$

De esta forma, se apelará a la "razón humana dialogante; no soberana pero sí autónoma" para el afrontamiento de muchos problemas éticos actuales, pues no se considera que sea posible una moral unívocamente deducible de los principios cristianos. ${ }^{68}$ Ya el propio Faus había reivindicado hacía años a la posmodernidad como fundadora de un verdadero diálogo, consecuencia -afirmaba citando a Vattimo- de la "imposibilidad de la metafísica" ${ }^{69}$ Por otra parte, se aspira a un modelo de catolicidad lejos de todo centralismo, sino construido "en y a partir de" las iglesias locales. También en la defensa del ecumenismo o unión de las iglesias cristianas se hace el énfasis especialmente en la reunión en la diversidad, hablándose preferentemente de "omni-versalismo" más que de "universalismo".

Todo lo anterior, como no podía ser menos, marcará la existencia de unas relaciones tensas y conflictivas con la jerarquía eclesiástica, algo que ya venía dado por la propia vinculación del centro con la teología de la liberación desde sus comienzos. Así, la cabeza más famosa y visible del centro, representada por Faus -cuyos problemas con la jerarquía católica venían ya de lejos-, se adscribirá a algunas declaraciones públicas de contestación a la línea oficial de la Iglesia durante los pontificados de Juan Pablo II y Benedicto XVI, aparte de lo manifestado ya, junto a otros, en las

\footnotetext{
64 Alegre, Xavier, et al.: “¿Qué pasa en la Iglesia?”, Cuadernos Cristianismo y Justicia, 153 (2008), p. 28.

65 González Faus, José Ignacio: Post-modernidad... p. 23.

66 González Faus, José Ignacio: ¿Dios?... p. 28.

67 Alegre, X. et al.: ¿Qué pasa?... p. 25.

68 Ibídem, p. 28. Cristianisme i Justícia: El tercer ..., pp. 1-27.

69 González Faus, José Ignacio: Post-modernidad... p. 17.
} 
propias publicaciones del centro. ${ }^{70}$ Destaca, por ejemplo, su adhesión a un manifiesto del año 2000 en el que teólogos de quince países se desmarcaban de la declaración vaticana Dominus Iesus "Sobre la unicidad y la universalidad salvífica de Jesucristo y de la Iglesia". ${ }^{71}$ El propio Faus, por otra parte, sostuvo un forcejeo personal con el obispo de Córdoba en 2013 por el hecho de haber sido invitado a participar en un congreso trinitario en esta misma ciudad. ${ }^{72}$ Con el acceso de Bergoglio a la cátedra petrina, y su voluntad de realizar reformas en profundidad, el jesuita catalán se unirá a la ola de iniciativas, llevadas a cabo por distintos teólogos y religiosos considerados también progresistas, como Pagola, Tamayo, Masiá, Estrada o Picaza, para

reclamar a Francisco que no ceda ante las presiones de los sectores conservadores y para que aborde con coraje las muchas reformas que esperan los católicos en materia de familia, matrimonio, relaciones personales, aborto, homosexualidad, etc. ${ }^{73}$

\section{Conclusiones}

Lo que parece deducirse de este estudio de la evolución del Centro desde su fundación es una continua relativización del mensaje cristiano, posible de detectar desde diferentes prismas. Relativización desde el punto de vista del escepticismo, expresamente declarado, hacia la propia naturaleza solidaria del hombre y hacia sus capacidades para construir un mundo que supere definitivamente la injusticia, el sufrimiento y la irracionalidad, unida a la percepción del alejamiento de Dios. Se afirma que "el hombre es en algún sentido más pequeño de lo que pretende", y que "la realidad de este valle de lágrimas quizá "no da mucho más de sí", descubrimientos que deberíamos al pensamiento posmoderno. ${ }^{74}$

Los autores de CJ parecen bascular, a lo largo de la trayectoria de los más de treinta años de existencia del centro, entre varias concepciones del mundo y del hombre. Dentro de su propio universo de fe cristiana, parece irse efectuando una transición entre una fe en una verdad de carácter revelado, que en un principio se considera absoluta, hacia una verdad con creciente peso de ingredientes históricos, que se fundamenta en última instancia en la figura del Jesús histórico y su praxis en aquel tiempo. La propia teología de la liberación, entre otras fuentes, les iría situando en posicionamientos intelectuales que justificarían partir, en sus análisis, de una creciente concreción histórica. Todo ello proporcionaría los argumentos hacia posturas cada vez más "antidogmáticas" que enfrentarían a la institución y a algunas de sus figuras más destacadas con la jerarquía eclesial. Por otro lado, entre el propio bagaje

70 Ya un artículo de El País del año 81 alude, por ejemplo, a que el propio Faus había sido vetado para enseñar en algunas universidades católicas (S.A.: "Continuismo en la comisión permanente de la conferencia episcopal", El País, 28 de febrero de 1981. http://elpais.com/diario/1981/02/28/sociedad/352162806 850215.html.

71 Bedoya, Juan G.: “Objetivo: recuperar España para la Iglesia romana”, El País, 14 de junio de 2012. http:// sociedad.elpais.com/sociedad/2012/06/14/vidayartes/1339699602_867743.html; Bedoya, Juan G.: "Teólogos de 15 países firman un manifiesto contra la declaración papal sobre las iglesias”, El País, 5 de octubre de 2000. http://elpais.com/diario/2000/10/05/sociedad/970696805_850215.html.

72 Miranda, Luis: "El obispo y el teólogo heterodoxo", ABCandalucía.es. Córdoba, 17 de mayo de 2013. http:// sevilla.abc.es/cordoba/20130517/sevp-obispo-teologo-heterodoxo-20130517.html.

73 Bedoya, Juan G.: "La Iglesia católica necesita mucho más que "un revoque de fachada“, El País, 14 de octubre de 2015. http://internacional.elpais.com/internacional/2015/10/14/actualidad/1444843781_840410.html.

74 González Faus, José Ignacio: Post-modernidad..., p. 16. 
intelectual se encontrarían asimismo algunos restos del utillaje conceptual marxista y elementos tomados de la filosofía y los ideales de la modernidad y de las concepciones políticas socialdemócratas. No obstante, puede observarse una decantación final por una opción posmoderna, aun cuando con algunos ecos marxistas y de la modernidad, y un regreso a la concepción tradicional de la responsabilidad personal de carácter cristiano. Esto es, un sentido de la exigencia ética personal que encuentra mucho menos anclaje que antes del giro iniciado en 1989 en las dinámicas impersonales y colectivas de una historia que era concebida con un sentido y un fin, pero que se hallan en buena medida desdibujados a partir de entonces.

\section{Referencias bibliográficas}

Alegre, Xavier, et al.: “¿Qué pasa en la Iglesia?”, Cuadernos Cristianismo y Justicia, 153 (2008), pp. 1-32.

Almansa Pérez, Rosa María: "Evolución de las Declaraciones universales de derechos y relativización de las fuentes de la moral religiosa”, en Miguel Rodríguez Blanco; Juan González Ayesta (coords.): Religión y Derecho Internacional, Granada, Comares, 2013, pp. 87-125.

Bastida Vilá, Benjamín: "La revolución del Este. Análisis de un fracaso", Cuadernos Cristianismo y Justicia, 40 (1991), pp. 1-13.

Bastida Vilá, Benjamín: "El reto del trabajo“, Cuadernos Cristianismo y Justicia, 93 (1999), 1-27.

Batista Libânio, Joâo: Teología de la liberación: guía didáctica para su estudio, Santander, Sal Terrae, 1989.

Bedoya, Juan G.: "Teólogos de 15 países firman un manifiesto contra la declaración papal sobre las iglesias", El País [en línea], 5 de octubre de 2000. Disponible en: http://elpais.com/diario/2000/10/05/sociedad/970696805_850215.html [consultado el 28 de septiembre de 2016].

Bedoya, Juan G.: "Objetivo: recuperar España para la Iglesia romana”, El País [en línea], 14 de junio de 2012. Disponible en: http://sociedad.elpais.com/sociedad/2012/06/14/vidayartes/1339699602_867743.html [consultado el 28 de septiembre de 2016].

Bedoya, Juan G.: "La Iglesia católica necesita mucho más que "un revoque de fachada", El País [en línea], 14 de octubre de 2015. Disponible en: http://internacional. elpais.com/internacional/2015/10/14/actualidad/1444843781_840410.html [consultado el 28 de septiembre de 2016].

Berryman, Phillip, Teología de la Liberación: los hechos esenciales en torno al movimiento revolucionario en América Latina y otros lugares, México, Siglo XXI, 1989.

Boff, Leonardo: Iglesia: carisma y poder. Ensayos de eclesiología militante, Santander, Sal Terrae, 1982.

Camacho, Ildefonso: "Pagar los impuestos? Una polémica cuyo fondo es el futuro del Estado del Bienestar“"،, Cuadernos Cristianismo y Justicia, 36 (1989), pp. $1-36$.

Carrera Carrera, Joan: "En busca del Reino. Moral para un nuevo milenio", Cuadernos Cristianismo y Justicia, 101 (2000), pp. 1-27. 
Carrera Carrera, Joan: "Mundo global. Ética global”, Cuadernos Cristianismo y Justicia, 118 (2003), pp. 1-27.

Carrera Carrera, Joan: "Identidades para el siglo XX", Cuadernos Cristianismo y Justicia, 147 (2007), pp. 1-33.

Carrera Carrera, Joan: "Una relación difícil. Cristianismo y sociedad desde la perspectiva ética“, Cuadernos Cristianismo y Justicia, 170 (2010), pp. 1-32.

Carrera Carrera, Joan: "La revolución de cada día. Cristianismo, capitalismo y posmodernidad", Cuadernos Cristianismo y Justicia, 189 (2014), pp. 1-36.

Casanovas, Xavier: "Y con los impuestos y el sistema fiscal, ¿qué hacemos? \#201 electoral", Blog de Cristianisme y Justícia, 19 de junio de 2015. Disponible en: http://blog.cristianismeijusticia.net/?p=12425\&lang=es [consultado el 26 de septiembre de 2016].

Casanovas, Xavier: "Se confirma: Hacienda no somos todos", Blog de Cristianisme y Justícia, 13 de enero de 2016. Disponible en: http://blog.cristianismeijusticia. net $/ \mathrm{p}=13107 \&$ lang=es [consultado el 26 de septiembre de 2016].

Casaldáliga, Pedro; Vigil, José María: Espiritualidad de la Liberación, Santander, Sal Terrae, 1992.

Centre d' Estudis Cristianisme i Justícia: "Fundación Lluis Espinal (CJ)", Centre de Estudis Cristianisme i Justícia [en línea], S.f. https://www.cristianismeijusticia.net/es/fundaci\%C3\%B3n-lluis-espinal-cj [consultado el 26 de septiembre de 2016].

Centre d' Estudis Cristianisme i Justícia: "Los cuadernos de Cristianisme i Justícia", en Centre de Estudis Cristianisme i Justícia [en línea] https://www.cristianismeijusticia.net/es/quaderns [consultado el 24 de julio de 2017].

Comblin, José; González Faus, José Ignacio; Sobrino, Jon: Cambio social y pensamiento cristiano en América Latina, Madrid, Trotta, 1993.

"Continuismo en la comisión permanente de la conferencia episcopal", El País [en línea], 28 de febrero de 1988. Disponible en: http://elpais.com/diario/1981/02/28/ sociedad/352162806_850215.html [consultado el 28 de septiembre de 2016].

Cortina, Adela; Carreras, Ignasi: "Consumo...luego existo", Cuadernos Cristianismo y Justicia, 123 (2004), pp. 1-27.

Cristianisme i Justícia: Universalidad de Cristo. Universalidad del pobre. Aportación al diálogo interreligioso, Santander, Sal Terrae, 1995.

Cristianisme i Justícia: "El tercer milenio como desafío para la Iglesia“, Cuadernos Cristianismo y Justicia, 91 (1999), pp. 1-27.

Cristianisme i Justícia: "Cristianisme i Justícia. 30 años de reflexión por un mundo más justo", YouTube [en línea], 19 de octubre de 2011. https://www.youtube.com/ watch? $\mathrm{v}=\mathrm{KOeGzurUo8s} \# \mathrm{t}=64$ [consultado el 26 de septiembre de 2016].

Cristianisme i Justícia: "Transformemos el mundo desde el afecto y la ternura", $\mathrm{Pa}$ peles Cristianismo y Justicia, 231 (2016), pp. 1-4.

Díaz Salazar, Rafael: "Un nuevo ciclo para la izquierda", Cuadernos Cristianismo y Justicia, 59 (1994), pp. 1-20.

Durán, Elvira: “¿Hacia dónde va la democracia?”, Papeles Cristianismo y Justicia, 215 (2012), pp. 1-4.

Estrada, Juan Antonio: El cristianismo en una sociedad laica: cuarenta años después del Vaticano II (2a. ed.), Bilbao, Desclée de Brouwer, 2009.

García-Nieto, Joan: "Proyecto de sociedad en clave de Utopía", Cuadernos Cristianismo y Justicia, 27 (1989), pp. 1-22. 
Gesteira Garza, Manuel: La teología en la España del siglo XX, Bilbao, Desclée de Brouwer, 2004.

González de Cardedal, Olegario: La Iglesia en España, 1950-2000, Madrid, PCC, 1999.

González de Cardedal, Olegario: La teología en España (1959-2009). Memoria y prospectiva, Madrid, Encuentro, 2010.

González Faus, José Ignacio, et al.: La batalla de Puebla, Barcelona, Laia, 1980.

González Faus, José Ignacio: "Post-modernidad europea y cristianismo latinoamericano", Cuadernos Cristianismo y Justicia, 22 (1988), pp. 1-27.

González Faus, José Ignacio: "Veinticinco años de teología de la liberación (19711996): teología y opción por los pobres", en J. Busquets y M. Martinell (eds.), Fe i teologia en la història, Facultat de Teologia de Catalunya, Barcelona, 1997, pp. 615-634.

González Faus, José Ignacio: "La difícil laicidad", Cuadernos Cristianismo y Justicia, 131 (2004), pp. 1-24.

González Faus, José Ignacio: "Nada con puntillas: fraternidad en cueros. La lucha por la justicia en una cultura nihilista", Cuadernos Cristianismo y Justicia, 166 (2010), pp. 1-32.

González Faus, José Ignacio: "El naufragio de la izquierda“, Cuadernos Cristianismo y Justicia, 177 (2011), pp. 1-33.

González Faus, José Ignacio: “¿Dios?”, Cuadernos Cristianismo y Justicia, 190 (2014), pp. 1-36.

González Faus, José Ignacio; Pascual, María Luisa: “Cárceles y sociedad democrática", Cuadernos Cristianismo y Justicia, 45 (1992), pp. 1-24.

Gutiérrez, Gustavo: Teología de la Liberación. Perspectivas, $18^{\text {a }}$ edición, Salamanca, Sígueme, 2009.

Laguna, José: "Pisar la luna. Escatología y política", Cuadernos Cristianismo y Justicia, 195 (2015), pp. 1-36.

Laguna, José: "¿Y si Dios no fuera perfecto? Hacia una espiritualidad simpática". Cuadernos Cristianismo y Justicia, 102 (2000), pp. 1-23.

López, María-Paz: "Justo y necesario. Cristianisme i Justícia cumple 20 años de reflexión sobre fe, cultura y asuntos sociales", La Vanguardia [en línea], 9 de septiembre de 2001. Disponible en: http://hemeroteca.lavanguardia.com/preview/1992/11/29/pagina-52/34162769/pdf.html? search=cristianisme $\% 20 \mathrm{i} \% 20$ justicia [consultado el 26 de septiembre de 2016]

Lyotard, Jean-François: La condición postmoderna, Barcelona, Planeta, 1993.

Mateos, Óscar: "Hacia un nuevo contrato social", Papeles Cristianismo y Justicia, 217 (2013), pp. 1-5.

Melloni Ribas, Xabier: "Los ciegos y el elefante. El diálogo interreligioso". Cuadernos Cristianismo y Justicia, 97 (2000), pp. 1-24.

Miranda, Luis: "El obispo y el teólogo heterodoxo", ABCandalucía.es. Córdo$b a$ [en línea], 17 de mayo de 2013. Disponible en: http://sevilla.abc.es/cordoba/20130517/sevp-obispo-teologo-heterodoxo-20130517.html [consultado el 28 de septiembre de 2016].

Miralles, Josep: "El Estado del bienestar. Debates y perspectivas", Cuadernos Cristianismo y Justicia, 49 (1992), pp. 1-19.

Oller Sala, Ma Dolors: "Un futuro para la democracia. Una democracia para la gobernabilidad mundial”, Cuadernos Cristianismo y Justicia, 115 (2002), pp. 1-29. 
Oller Sala, Ma Dolors: "Construir la convivencia. El nuevo orden mundial y las religiones", Cuadernos Cristianismo y Justicia, 157 (2008), pp. 18-20.

Oller Sala, Ma Dolors; Seminario De Profesionales Jóvenes De Cristianismo y Justicia: "Ante una democracia de baja intensidad, la democracia a construir", Cuadernos Cristianismo y Justicia, 56 (1993), pp. 1-38.

Peña-Ruiz, Henry; Tejedor De La Iglesia, César: Antología laica. 66 textos comentados para comprender el laicismo, Universidad de Salamanca, 2009.

Provincia Mexicana de la Compañía de Jesús: "Congregación general 32. Decreto 4: Nuestra misión hoy", Pedagogía Ignaciana [en línea], 1974-1975. Disponible en: http://pedagogiaignaciana.com/GetFile.ashx?IdDocumento $=467$ [consultado el 26 de septiembre de 2016].

Rawls, John: La justicia como equidad, Paidós, Barcelona, 2002.

Renau, Jesús: "Formación social en la escuela y proyecto de sociedad (una visión cristiana)", Cuadernos Cristianismo y Justicia, 48 (1992), pp. 1-18.

Riera i Figueras, Francesc: "El Centro de Estudios ,Cristianisme i Justicia"”, Iglesia Viva: Revista de Pensamiento Cristiano, 134-135 (1988), pp. 285-292.

Sebastián, Luis de: "Capitalismo y democracia en el siglo XXI", Cuadernos Cristianismo y Justicia, 99 (2000), pp. 1-25.

Segundo, Juan Luís: "Estudio crítico sobre la Teología de la Liberación. La respuesta de J. L. Segundo al primer documento Ratzinger (síntesis y guía de lectura)", Cuadernos Cristianismo y Justicia, 13 (1986), pp. 1-21.

Tamayo, Juan José; Fornet-Betancourt, Raúl (eds.): Interculturalidad, diálogo interreligioso y liberación: I Simposio Internacional de Teología Intercultural e Interreligiosa de la Liberación: Barcelona, 11-12 de julio de 2004, Navarra, Verbo Divino, 2004.

Tamayo, Juan José: Otra teología es posible. Pluralismo religioso, interculturalidad y feminismo, Barcelona, Herder, 2011.

Vives, Josep: "La democracia, más allá de los ídolos", Cuadernos Cristianismo y Justicia, 125 (2004), pp. 1-26. 